\title{
THE GENESIS OF KIMBERLITE AND ASSOCIATED ROCKS: STRONTIUM ISOTOPIC EVIDENCE
}

D. R. Barrett, Bernard Price Institute of Geophysical Research, University of the Witwatersrand, Johannesburg.

Strontium isotopic tracer techniques have been applied in the investigation of materials from kimberlite pipes. Studies were made on 13 samples of fresh kimberlite, 20 samples of peridotite-, eclogite-, phlogopite-, and diopside nodules, and mineral concentrates from kimberlite groundmass and nodules ( 42 micas, 21 other samples, mainly clinopyroxenes). This work was complemented by $\mathrm{K}, \mathrm{Rb}$ and $\mathrm{Sr}$ concentration determinations (employing isotope dilution) and petrographic, electron-probe and contamination studies (including acid leaching and ground-water analyses).

Sr-isotopic compositions were mostly determined on tracer-free samples. They are in general accurate to $t 0,0003(1 \sigma)$. The accuracy of concentration data was $20,5 \% . \mathrm{Sr}^{87} / \mathrm{Sr}^{86}$ o refers to the strontium ratio $\sim 100 \mathrm{~m} . \mathrm{y}$. ago (i.e. at pipe emplacement).

RESULTS

1. Assessment of samples: The significance of the results hinges on whether the samples represent uncontaminated material. Al though it is widely thought that kimberlite inclusions have suffered contamination, the evidence presented below indicates that in the carefully selected samples studied this is minimal, and has not significantly affected the purified minerals.

Leaching of nodular samples with cold dilute $\mathrm{HCl}$ showed two distinguishable "contaminants". Contaminant "A" (observed only in peridotite diopsides and one Wesselton eclogite total rock), is similar to fresh kimberlite with $\mathrm{Sr}^{87} / \mathrm{Sr}^{86} \sim 0,705, \mathrm{~K} / \mathrm{Rb} \sim 120$ and relatively high $\mathrm{Rb}$ and $\mathrm{Sr}$ contents. This gives rise to the effect that unleached diopsides have lower $\mathrm{Sr}^{87} / \mathrm{Sr}^{86}$ o than leached samples. Contaminant "B" (found in eclogite- and diopside-nodules) has high $\mathrm{Sr}^{87} / \mathrm{Sr}^{86}(\sim 0,710)$, high $\mathrm{K} / \mathrm{Rb}(\sim 1000)$ and $10 \mathrm{w} \mathrm{Rb}$ and $\mathrm{Sr}$ contents. Such material could be an alteration product (e.g. zeolite and kelyphite) formed by percolating ground waters $\left(\mathrm{Sr}^{87} / \mathrm{Sr}^{86} \sim 0,712-0,720\right)$. Leached and unleached omphacites do not show significant differences in $\mathrm{Sr}^{87} / \mathrm{Sr}^{86}$ values indicating that these are not dominated by this contaminant. Leach solutions from peridotite whole rocks showed intermediate character.

Petrographic assessment of the eclogites revealed, in some cases, that phlogopitisation occurred before kelyphitisation. The latter is envisaged as occurring at about the time of, or since, emplacement (Kramers 1973). Some peridotite mica was considered primary with lesser amounts of secondary mica. Petrographic assessment of the selected nodular samples showed limited serpentinisation and other alteration.

Also relevant are the following points:

i) Although crustal contamination of whole rocks is possible, it appears that contaminating $\mathrm{Sr}$ has not had a serious effect on the purified mineral concentrates since juxtaposed samples of the 
types studied, all of which would be expected to be similarly affected, retain distinct and individual ranges in $\mathrm{Sr}^{87} / \mathrm{Sr}^{86}$, ratios.

ii) The peridotite mica and diopside were probably in isotopic equilibrium with each other (and $\sim$ with the whole rock) at the time of emplacement, implying minimal contamination.

iii) Leaching experiments show that ground-water type material could have affected the nodules (particularly eclogites). Ground water would be expected to raise the $\mathrm{Sr}^{87} / \mathrm{Sr}^{86}$ ratios: there is, however, no relationship between $\mathrm{Sr}^{87} / \mathrm{Sr}^{86}$ ratio and degree of freshness. The contaminant appears to be similar to that which has affected fresh kimberlite (see companion Barrett-Berg paper).

iv) In view of the consistent age data of most micas (see companion Barrett-Allsopp paper) it would seem that any alteration occurred mainly about the time of pipe formation.

2. (a) Nodular Inclusion and Kimberlite Data (See Figure): The most striking results obtained are the generally significant differences in $\mathrm{Sr}^{87} / \mathrm{Sr}^{86}$ of kimberlite and of well-purified clinopyroxenes from different hosts. They increase in the following order: diopside nodule diopsides $(0,703-0,704)$; the freshest kimberlite $(0,704-$ $0,705)$; eclogite omphacite $(0,7047-0,7062)$; peridotite diopsides $(0,7060-0,7075)$.

All the freshest eclugite total rocks and the pyroxenes lie to the left of $\mathrm{G}$ with $\mathrm{Rb} / \mathrm{Sr}$ ratios too low to account for their observed $\mathrm{Sr}^{87} / \mathrm{Sr}^{86}$ values. They cannot therefore be primary mantle material. In contrast, similar reasoning shows that peridotite nodule total rocks, lying to the right of $G$, could be undifferentiated mantle.

$\mathrm{K} / \mathrm{Rb}$ ranges tend to overlap: fresh kimberlite $(90-210)$; micas (95 - 380); peridotite total rocks ( 200$)$; peridotite diopsides ( 235); eclogite total rocks ( 200 - 500); eclogite omphacites (250 5,000); diopside nodule diopsides $(850$ - 970). The contrasting clinopyroxene values are noteworthy.

These results substantiate and extend the work of Allsopp et al. (1969) and Berg and Allsopp (1972).

2. (b) Eclogite: The eclogite minerals were not in isotopic equilibrium at pipe emplacement time. Eclogite mica has $\mathrm{Sr}^{87} / \mathrm{Sr}^{86}$ 。 $\sim 0,7082$ whereas omphacite has $\mathrm{Sr}^{87 / \mathrm{Sr}^{86} \sim 0,7055 \text {. It follows that }}$ much of the eclogite mica is not primary.

Relationships between eclogite and basalt have been previously suggested. For instance Allsopp et al. (1969) theorised about the possibility of an ideal eclogite (i.e. omphacite and garnet only) which might be parental to oceanic tholeite. The $\mathrm{Sr}^{87} / \mathrm{Sr}^{86}$ values now obtained for omphacite are too high to be consistent with such a mode1.

A possible relationship between eclogite and Stormberg basalts is suggested by the similarity in $\mathrm{K} / \mathrm{Rb}, \mathrm{K}, \mathrm{Rb}, \mathrm{Sr}$ and $\mathrm{Rb} / \mathrm{Sr}$ values if the freshest eclogites are considered. On the other hand, assuming a mean $\mathrm{Rb} / \mathrm{Sr}$ ratio, $\mathrm{Sr}^{87} / \mathrm{Sr}^{87}$ values $(200 \mathrm{~m} \cdot \mathrm{y}$. ago) of the freshest eclogite total rocks are too high to conform with the implied simple relationship; the similarity of most of the data would appear to be fortuitous. 
Only "ideal" eclogite (omphacite, garnet and possible primary mica) could be comagmatic with the basalts, in which case even the freshest eclogite total rocks must have been subsequently contaminated by a high $\mathrm{Sr}^{87} / \mathrm{Sr}^{86}$ component. The Roberts Victor eclogite micas indicate an age of $\sim 126 \mathrm{~m} . \mathrm{y}$. but the data are more scattered than those of micas from other sources. The kelyphitisation of eclogites may be the responsible factor; from this aspect too it would appear that the eclogites have been contaminated. Berg (1968) considers that phlogopite may result from alteration involving addition of alkalis from kimberlite whilst still in a fluid state. Contrasting $\mathrm{Sr}^{87} / \mathrm{Sr}^{86}$ o values for fresh kimberlite and mica (this work) suggest that such a model is untenable.

2. (c) Peridotite: In contrast to the eclogite mica-pryoxene pair, peridotite micas and diopsides have very similar $\mathrm{Sr}^{87} / \mathrm{Sr}^{86}$ 。 values $(20,707)$. Possibly there was isotopic equilibrium between these minerals until pipe emplacement. Assuming a $\mathrm{Sr}^{87} / \mathrm{Sr}^{86}$ value of $\sim 0,702$ for the source of these peridotite nodules and an average mica $\mathrm{Rb} / \mathrm{Sr}$ ratio (and that the increase in this ratio to 0,707 has been a result of $\mathrm{Sr} 87 *$ production in the mica only) then a lengthy association $\left(\sim 800 \mathrm{~m} \cdot \mathrm{y}_{\bullet}\right)$ of the two minerals is implied.

2. (d) Origin of Nodules: Eclogite omphacites having lower $\mathrm{Sr}^{87} / \mathrm{Sr}^{86}$ o from such material (by a process such as suggested by $0^{\prime}$ Hara and Yoder 1967). Since a cumulate origin for eclogite is consistent with other data, it is possible that garnet peridotite of another type with low $\mathrm{Sr}^{87} / \mathrm{Sr}{ }^{86}$ values yields picritic partial melts. Eclogite (and basalt) could be derived from this melt. The peridotites possibly represent xenoliths of mica bearing mantle zones.

2. (e) Kimberlite: Fresh kimberlite with lower $\mathrm{Sr}^{87} / \mathrm{Sr}^{86}$ ratios than its eclogite and peridotite inclusions cannot be derived from such material. The nodules are xenolithic. Only diopside nodules $\left(\mathrm{Sr}^{87} / \mathrm{Sr}^{86}<0,704\right)$ could be representative of parental material. Alternatively they could be early cumulates from a "kimberlite" melt or merely accidental inclusions.

It is suggested that kimberlite has a deep origin, possibly in undepleted low $\mathrm{Sr}^{87} / \mathrm{Sr}^{86}$, garnet peridotite regions. Small degrees of partial melting give rise to a melt with carbonatitic affinities. Note that carbonatites have $\mathrm{Sr}^{87} / \mathrm{Sr}^{86}$ values of $0,702-0,705$ and $\mathrm{K} / \mathrm{Rb}$ ratios of $90-200$, very similar to fresh kimberlite. Differentiation within a rapidly ascending magma concentrates $\mathrm{Rb}$ relative to $\mathrm{K}$, giving rise to the observed $\mathrm{K} / \mathrm{Rb} \sim 140$. The melt intercepts and incorporates pre-existing garnet peridotite (probably micaceous) with $\mathrm{Sr}^{87 / \mathrm{Sr}^{86}}$ 0,707, and possibly phlogopite with $\mathrm{Sr}^{87} / \mathrm{Sr}^{86} \sim 0,710-0,714$. (Phlogopite nodules are believed to be of mantle origin, Clement 1973.) This mechanism could, together with percolating ground-water (see companion Barrett-Berg paper) give rise to the higher $\mathrm{Sr}^{87} / \mathrm{Sr}^{86}$ values of typical kimberlite and also account for the abundance of peridotite minerals and mica. Eclogite, where present, is incorporated too. If eclogite (or ideal eclogite) is related to basalt genesis the prevalence of eclogite at Roberts Victor may be due to the kimberlite having ascended along a Stormberg volcanic conduit which contains remnant eclogite. 


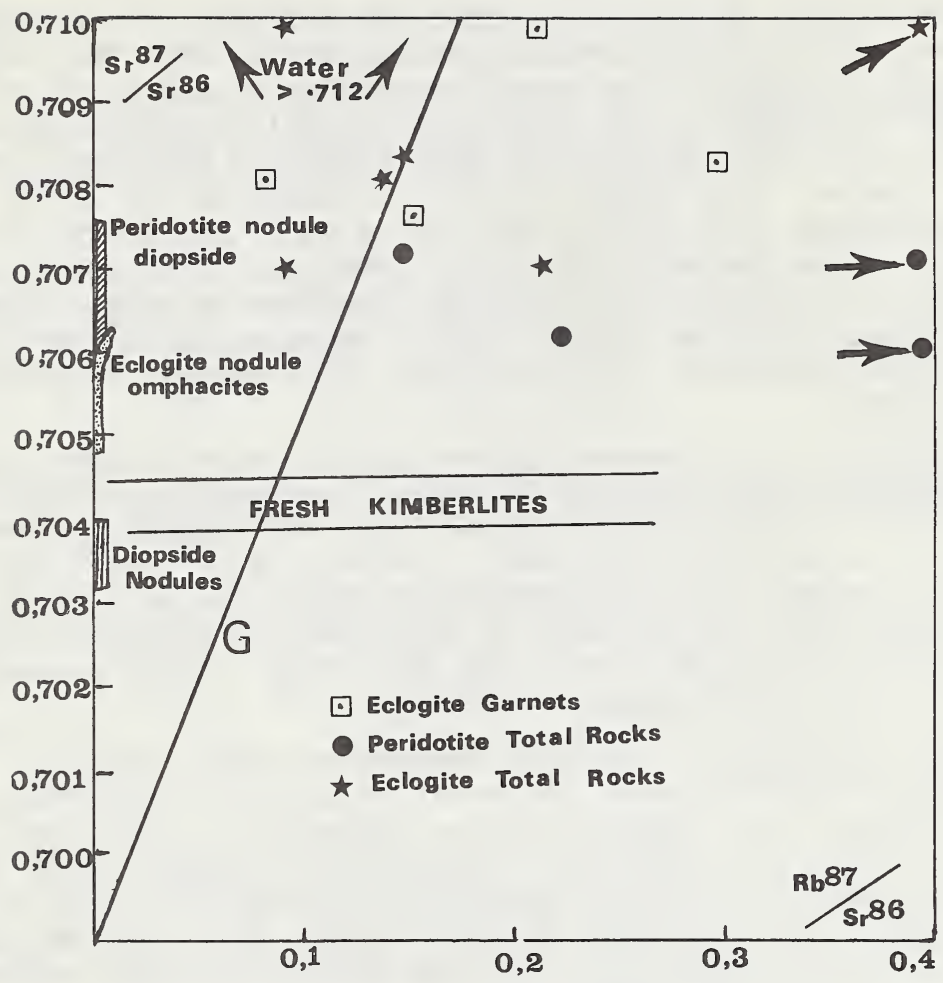

Figure: Sketch of Isochron Diagram

All points on the generating line 'G 'have $\mathrm{Rb}^{87} / \mathrm{Sr}^{86}$ ratios sufficient to account for their observed $\mathrm{Sr}^{87} / \mathrm{Sr}^{86}$ ratios over a period of 4,6 $\mathrm{b} \cdot \mathrm{y}$.

\section{REFERENCES}

Allsopp, H.L., Nicolaysen, L.O., and Hahn-Weinheimer, P. 1969. Earth \& Planet. Sci. Letters, 5, 231-244.

Berg, G.W. 1968. Amer. Mineral. 53, 1336-1346.

Berg, G.W., and Allsopp, H.L. 1972. Earth \& Planet. Sci. Letters, $16,27-30$.

Clement, R. 1973. (Personal communication)

Kramers, J. 1973. (Personal communication)

O'Hara, M.J., and Yoder (Jr.) H.S. 1967. Scott. J. Geol. 3(1), 67-117. 